\title{
Rice straw and energy reed fibers reinforced phenol formaldehyde resin polymeric biocomposites
}

\author{
K. M. Faridul Hasan (D) Péter György Horváth · Miklós Bak · Duong Hung Anh Le • \\ Zsuzsanna Mária Mucsi · Tibor Alpár
}

Received: 18 March 2021 / Accepted: 16 June 2021/Published online: 23 June 2021

(C) The Author(s) 2021

\begin{abstract}
Herein, natural fiber (energy reeds and rice straw) reinforced with phenol formaldehyde (PF) polymeric resin biocomposites are developed and reported in this study. The dimensions of energy reeds and rice straws used for this research were $0.5-1.66 \mathrm{~mm}$ and $0.1-3.55 \mathrm{~mm}$, respectively. The hot-pressing technology was used for manufacturing the biocomposites. The proportions for mixing of rice
\end{abstract}

Supplementary Information The online version contains supplementary material available at https://doi.org/10.1007/ s10570-021-04029-9.

K. M. F. Hasan $(\bowtie) \cdot$ P. G. Horváth

M. Bak · D. H. A. Le · Z. M. Mucsi · T. Alpár ( $\square)$

Simonyi Károly Faculty of Engineering, University of

Sopron, Sopron, Hungary

e-mail: k.m.faridul.hasan@phd.uni-sopron.hu

T. Alpár

e-mail: alpar.tibor@uni-sopron.hu

D. H. A. Le

Innovation Centre, University of Sopron, Sopron,

Hungary

D. H. A. Le

Department of Engineering Mechanics, Faculty of Applied Science, Ho Chi Minh City University of Technology (HCMUT), 268 Ly Thuong Kiet Street, District 10, Ho Chi Minh City, Vietnam

D. H. A. Le

Vietnam National University Ho Chi Minh City, Linh Trung Ward, Thu Duc District, Ho Chi Minh City, Vietnam straw/energy reed fibers in composite systems were 90/0, 54/36, 36/54, and 0/90 whereas remaining 10\% were belong to PF resin. The nominal densities of the biocomposite panels were $680 \mathrm{~kg} / \mathrm{m}^{3}$, however the actual densities were $713.655,725,742.79$, and $764.49 \mathrm{~kg} / \mathrm{m}^{3}$. The main objective of this study is to develop hybrid biocomposites from different proportions of energy reeds and rice straw fibers using PF resin and to find the convenient ratio and materials for biocomposites production. The obtained results demonstrate that mechanical properties and stability against the moisture increases with the increase of energy reeds loading in the composite systems. The biocomposite developed from 100\% energy reeds provided the higher mechanical properties compared to $100 \%$ rice straw. The thermal and morphological properties of the produced biocomposite materials were investigated and found significant. The thermomechanical properties of the composite materials increase with the increase in energy reed fiber loading in composite system. Furthermore, the coefficient of variation $\left(\mathrm{R}^{2}\right)$ also demonstrates a positive attributions of energy reed fibers loading in composite systems. Moreover, the overall performances of the developed biocomposite panels demonstrate them as potential and novel candidate to the composite community in the coming times. 


\section{Graphical abstract}

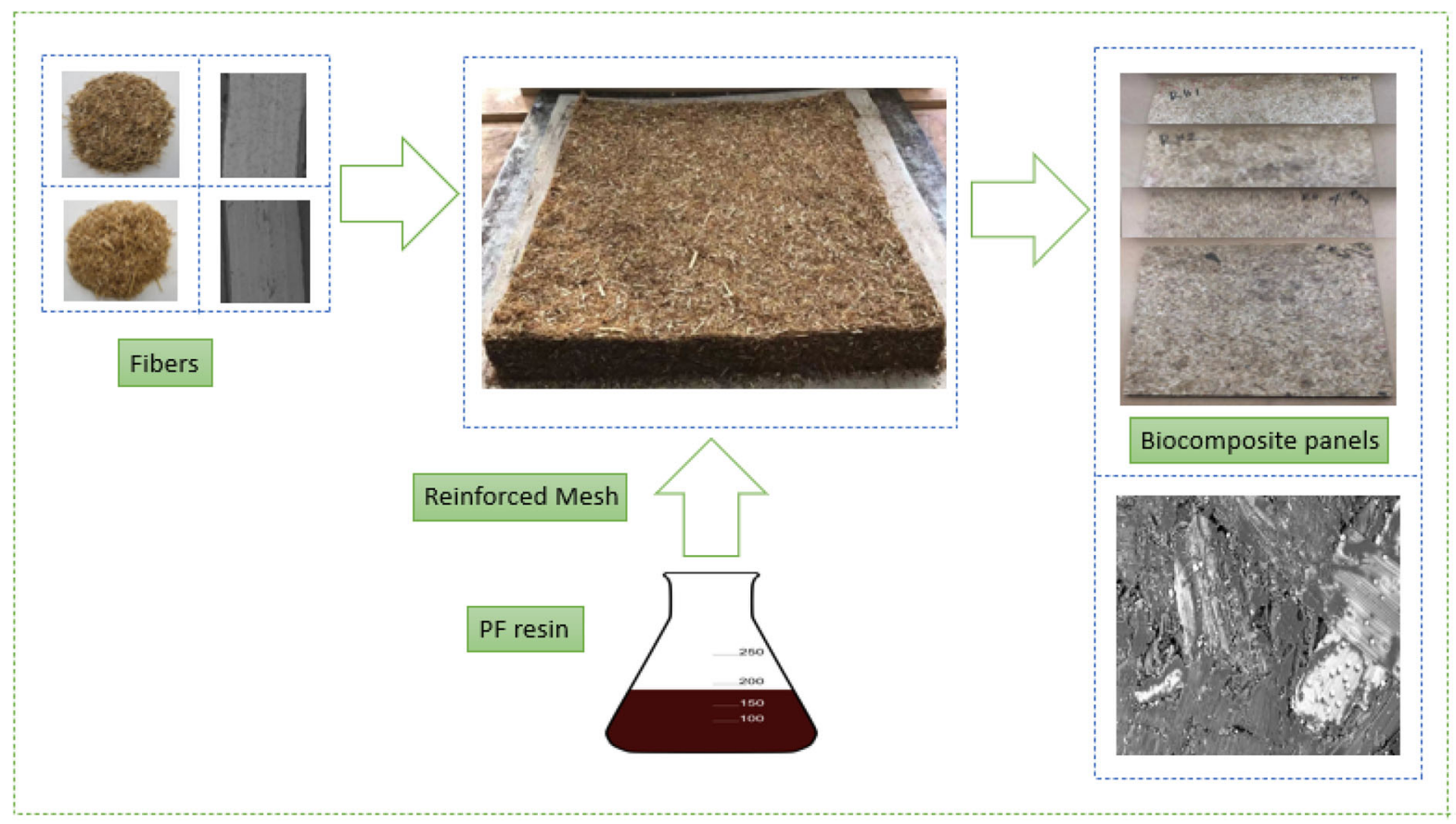

Keywords Natural fiber - Biocomposites . Mechanical performance Physical properties . Sustainable products

\section{Introduction}

Sustainable biobased materials are getting attentions throughout the globe continuously to minimize the burdens from environment. The European manufacturing companies are trying to find out more biodegradable, strong, and competitive raw materials for composites production. However, sustainability and innovative design of the product is getting priority to fulfill this purpose. Moreover, the plenty of plantbased materials are getting extensive attentions as they are considered as the most common, prominent, and renewable sources of raw materials available everywhere (Fuqua et al. 2012; Gallos et al. 2017; Hasan et al. 2021a; Jagadeesh et al. 2020; Ma et al. 2014; Mahmud et al. 2021; Matsuzaki 2016; Mokhothu and John 2017; Ramamoorthy et al. 2015; Rangappa et al. 2020; Sanjay and Siengchin 2021; Shubhra 2010; Thyavihalli Girijappa et al. 2019; Wang et al. 2015;
Xia 2016). Still, there are enormous plants remaining around the world which could be explored further through implementing state of the art technologies for converting them into suitable products as they are nontoxic in nature, biodegradable, renewable, and consume less energy to process which would facilitate the composite community. Furthermore, the hygroscopic characteristics (Li et al. 2018; Nouri et al. 2020; Yin et al. 2020) of plant-based materials provide healthier environment when the associated biocomposites are used for indoor applications. As the peoples are spending a long time indoor environment, hence it is required to keep the indoor air safer. However, plantbased materials possess a high capability to ensure a balance in the indoor relative humidity and temperatures especially for construction materials (Antunes et al. 2019). There are lots of researches conducted on commonly used woods (like poplar, scots pine, hornbeam, oak, beech, etc.) (Ferdosian et al. 2017; Hasan et al. 2021g, 2021h) and natural fibers (like hemp, flax, jute, sisal, ramie, and so on) (Faruk et al. 2012; Getme and Patel 2020; Gholampour and Ozbakkaloglu 2020; Holbery and Houston 2006; Rangappa et al. 2020; Sanjay et al. 2019) to utilize them as reinforcement material for developing 
biocomposites. However, still now, the research on hybrid composites development through utilizing energy reeds available in central Europe and rice straws are not studied yet to make them usable as a prominent biocomposite material.

Energy reed plants are grown nearby the lake shores and sea. There are some organizations like Energianövény-Team Kft., company Lengyeltóti, Hungary is working since 2006 for harvesting energy reeds in eastern and central European countries (Energianövény 2021). However, the same company is also taking initiatives to expand the energy reeds cultivation in some other neighboring countries of Hungary like Romania, Slovakia, and so on from 2017 (Energianövény 2021). The energy reed plants materials could potentially be used as suitable raw materials for food packaging, biomass heat power, and afterall high strength composite panels (Energianövény 2021). The energy reeds are used to produce bioenergy in some European countries like Finland (67 2008), however the potential applications on composite field is needed more attempts to explore. In this regard, it could be an interesting work to explore more viable options of fiber materials and processing methods to enhance the performance characteristics of sustainable products. Interfacial bonding between the fiber and polymer is extremely important. One of the possible reason behind the poor internal bonding strengths maybe the poor interfacial adhesion between the fibers and matrix. However, the pretreatment could facilitate with the improved fiber to matrix interactions (Hasan et al. 2020b) which could consequently increase the mechanical performances of the biocomposites as well. In this regard, pretreated energy reed is attempted to reinforce with PF resin through hybridized with another prominent natural resources like rice straw. It is found that the performance of the biocomposite panels increased with the increase of energy reeds fiber content in the composite systems. However, unfortunately, according to our knowledge, still now no research on energy reed fiber reinforced polymeric composites are found yet to carry on with the comparative study.

Rice is extensively grown throughout the world as a popular agricultural products (Xie et al. 2015). Rice straw is a common agricultural byproduct which is inexpensive and abundantly available as the naturally derived waste material having no commercial values that is why generally burnt or thrown away in the field for disposal after the extractions of rice (Basta et al. 2013; Pham et al. 2017). However, the burning and associated disposals create some extra burdening effects to the environments through generating $\mathrm{CO}_{2}$. Nevertheless, the rice straws generated from rice milling industries could be utilized as the prominent biocomposite material. There is around $20 \%$ of total rice product is considered as the byproduct materials (Rout and Satapathy 2012). The polymeric components present in rice husk (Table 1) demonstrates that cellulose is the main chemical component here like as other natural fibers (Mahmud et al. 2021). There are also significant presence of lignin and hemicellulose in the polymeric structures of rice husk. However, the asmentioned rice straw could be conveniently used for biocomposites productions too. El-Kassa et al. (ElKassas and Mourad 2013) reported about the rice straw reinforced urea formaldehyde resin composites where they found $24.00 \mathrm{MPa}$ MOR (modulus of rupture), $2850 \mathrm{MPa} \mathrm{MOE}$ (modulus of elasticity), and $0.50 \mathrm{MPa}$ IBS (internal bonding strength). Zhang et al. (Zhang and $\mathrm{Hu}$ 2014) developed hybrid composites from rice straw and coir fibers reinforced with PF resin and found $30.23 \mathrm{MPa}$ MOR, 4.55 GPa MOE, $0.41 \mathrm{MPa}$ IBS, and $13.09 \%$ TS (thickness swelling) for $100 \%$ rice straw and $27.16 \mathrm{MPa}$ MOR, 2.92 GPa MOE, 1.00 MPa IBS, and 8.06 TS for 50\% rice straw and $50 \%$ coir fibers for medium density fiberboards $\left(728 \mathrm{~kg} / \mathrm{m}^{3}\right)$. However, still now, no researches performed yet on energy reeds and rice straw reinforced hybrid polymeric composites.

Moreover, the pretreatment of natural fibers could facilitate with the enhancements in thermomechanical performances in the composite systems through improving the fiber to matrix interactions (Hasan et al. 2020a). There are different pretreatment methods like mercerization, acetylation, etherification, peroxide treatment, graft copolymerization, benzoylation, and so on for natural fibers surface modification (Kalia et al. 2009). However, the alkaline pretreatment method is used for this research to treat the energy reed and rice straw materials before the fabrications. In order to achieve the better performance characteristics through fiber treatment, it is required to use an optimum concentrations of alkaline reagents like $\mathrm{NaOH}$ or $\mathrm{Na}_{2} \mathrm{CO}_{3}$ (El-Sabbagh 2014; Njoku et al. 2019; Zhang et al. 2018). The possible reaction mechanism of energy reed and rice straw materials are shown in equation (1) and (2). On the other hand, 
Table 1 Chemical components present in reeds fiber and rice husk material

\begin{tabular}{lll}
\hline Constituent polymers & Energy reed fiber (Wahid et al. 2015) & Rice straw fiber (Xie et al. 2015) \\
\hline Cellulose & 50.3 & 35.6 \\
Hemicellulose & 21.7 & 20.5 \\
Lignin & 15.0 & 16.8 \\
Mineral ash & 4.0 & 15 \\
Moisture content & - & 12.1 \\
\hline
\end{tabular}

in European countries, medium density fiber boards (MDFs) are widely produced and used composite materials. In this regards, both the rice straw and energy reeds are collected from central European regions to find out more diversified renewable materials for medium density biocomposite panels production.

$$
\begin{aligned}
& \text { Ricestraw }-\mathrm{OH}+\mathrm{Na}-\mathrm{OH} \\
& \quad \rightarrow \text { Ricestraw }-\mathrm{O}^{-}-\mathrm{Na}^{+}+\mathrm{H}_{2} \mathrm{O} \\
& \quad \text { Energyreeds }-\mathrm{OH}+\mathrm{Na}-\mathrm{OH} \\
& \quad \rightarrow \text { Energyreeds }-\mathrm{O}^{-}-\mathrm{Na}^{+}+\mathrm{H}_{2} \mathrm{O}
\end{aligned}
$$

The mechanical properties found from rice husk reinforcement is lower compared to energy reeds. However, the incorporations of energy reeds with the rice husks enhanced the performances of developed biocomposite panels due to the attribution of positive hybrid reinforcement effects. Moreover, this research work would facilitate the biocomposite panel manufacturers with a sustainable and novel materials from renewable sources, where energy reed fibers could function as a new reinforcement biomaterial.

\section{Materials and methods}

\section{Materials}

The energy reeds (Miscanthus spp.) were collected from Energianövény-Team Kft., company located in Lengyeltóti, Hungary. The rice straw was received from local areas of central Europe (Hungary). However, both the rice straw and energy reeds (Fig. 1) were dried at ambient temperature and defibrated through using a defibrating machine. The fiber materials were sieved for ensuring homogeneous fiber dimensions before going to composite productions.
Phenolic resin like PF was supplied by Chemco, a. s. in Slovakia for the purpose of research. The PF is reddish brown in appearance, liquid, and viscous. However, the dynamic viscosity of the PF resin was within 240-1080 mPa.s, density $1210 \pm 20 \mathrm{~kg} / \mathrm{m}^{3}$, dry matter content minimum 48, $\mathrm{pH} 10-12$, and maximum free phenol content 0.1 (wt $\%$ ).

Methods

\section{Preparation of rice straw and energy reeds fiber}

The rice straw and energy reeds are long stem plant materials which were chopped around $30-40 \mathrm{~mm}$ in lengths by using a circular cutting equipment (DCS570N XJ model, Pennsylvania, United States). After that, both the rice straw and energy reeds were pretreated with $5 \%(\mathrm{w} / \mathrm{v})$ of $\mathrm{NaOH}$ for removing any impurities present in the raw plant materials. The excessive usage of alkaline reagents could damage the cells of cellulosic substrates (Hasan et al. 2021c; Rokbi et al. 2011), hence an optimum values of $\mathrm{NaOH}$ was used for this pretreatment (Mishra 2003). The materials were soaked in cold water for $24 \mathrm{~h}$ at basic $\mathrm{pH}$ medium (around 12.0). The treated rice straw and energy reeds were then washed with tape water for removing the excess impurities and mucus from the surfaces and dried in an oven drier for $30 \mathrm{~min}$ at $100{ }^{\circ} \mathrm{C}$. The $\mathrm{pH}$ of energy reed and rice straws were checked again after the treatments which was around 7.0. Moisture contents of the rice straw and energy reeds were checked after the drying and found to have around $9.3 \%$. Later, the rice straw and energy reed stems were defibrated using a defibrating machine (VZ 23,412, Dinamo Budapest, Hungary) without destroying the fibrils of the materials through adjusting the grain and grinders distance. All the fibrous materials were sieved using a Sieve analyzer from Fritsch 
Fig. 1 Physical and morphological photographs of energy reeds and rice husks: a Physical photographs of energy reeds; $\mathbf{b}$ SEM image of energy reeds; c Physical photographs of rice straw; d SEM image of rice straw

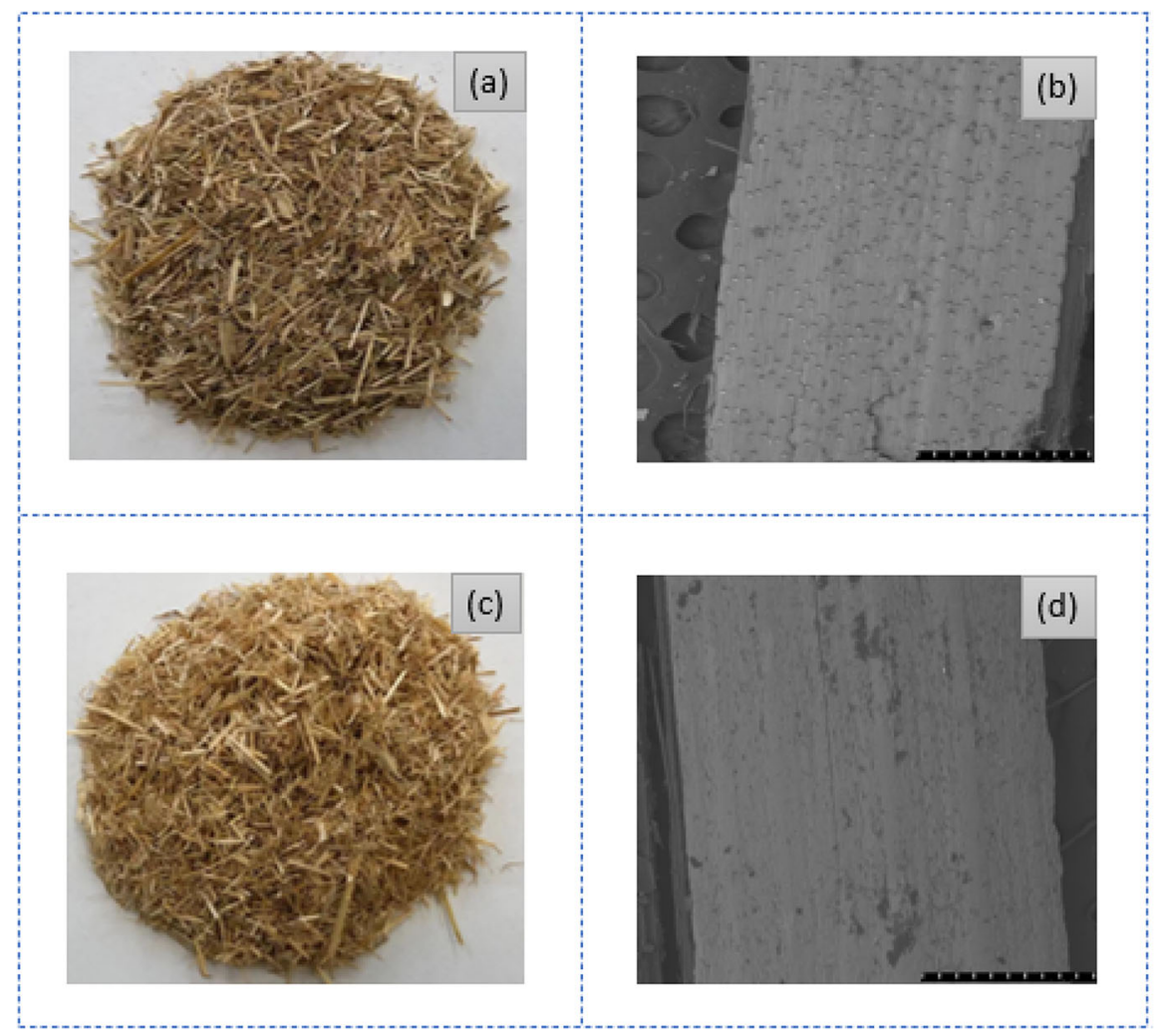

GmbH (ANALYSETTE 3Pro, Germany) having different dimensions from 0.1 to $3.55 \mathrm{~mm}$ for rice straws and $0.5-1.66 \mathrm{~mm}$ for energy reeds. The amplitude vibrations of the sieve analyzers were 1.0 for a $15 \mathrm{~min}$ duration of time for $100.0 \mathrm{~g}$ (randomly chosen) rice straw and energy reeds, respectively. It is found that the highest dimension of rice straw fibers were $44.1 \%$ and energy reeds were $44.6 \%$. However, $5.7 \%$ rice straw fibers dimension were within $2.55 \mathrm{~mm}, 27.6 \%$ fibers $3.55 \mathrm{~mm}, 10.6 \%$ fibers $0.5 \mathrm{~mm}, 11.1 \%$ fibers $0.1 \mathrm{~mm}$. On the other hand, $26.7 \%$ energy reeds were within $1.25 \mathrm{~mm}, 13.8 \%$ fibers $1.0 \mathrm{~mm}, 14.8 \%$ fibers were $0.5 \mathrm{~mm}$ in dimensions as shown in supplementary file (Fig. S1). Overall, the prepared sieved materials from rice straw and energy reeds were termed as the fiber materials.

\section{Production of biocomposites panels}

The hot pressing technology was implemented for manufacturing biocomposites from rice straw and energy reed fibers. Initially, the PF resin as per the recipe mentioned in Table 2 was sprayed uniformly to the fibers in a rotating drum blender. In case of first biocomposite panel (EH1) 90\% rice straw fibers were used but for biocomposite panel 4 (EH4) 90\% energy reed fibers were used. The biocomposite panel 2 (EH2) was produced from 54\% rice straw to $36 \%$ energy reeds, whereas the biocomposite panel 3 (EH3) by $36 \%$ rice straw and 54\% energy reed fibers. However, there were just only $10 \% \mathrm{PF}$ used for all the biocomposite panels. The moisture contents of the mat were considered as $12 \%$ and resin by $34 \%$ to

Table 2 Experimental design for rice straw and energy reed fibers reinforced PF biocomposite panels production

\begin{tabular}{lccc}
\hline Composite materials & $\begin{array}{l}\text { RS } \\
(\%)\end{array}$ & $\begin{array}{l}\text { ER } \\
(\%)\end{array}$ & $\begin{array}{l}\text { PF } \\
(\%)\end{array}$ \\
\hline EH1 & 90 & 0 & 10 \\
EH2 & 54 & 36 & 10 \\
EH3 & 36 & 54 & 10 \\
EH4 & 0 & 90 & 10 \\
\hline
\end{tabular}

${ }^{*} R S$ Rice straw, ER Energy reeds, and $P F$ Phenol formaldehyde resin 
calculate the recipe from the fractions. The mixed fibers were placed in a $400 \mathrm{~mm} \times 400 \mathrm{~mm}$ wooden frame through ensuring uniform spreading. Later, two $12 \mathrm{~mm}$ thickness steel rods were placed in the two sides of the mats for providing a specific thickness to the ultimate biocomposite panels. A hot press machine (G. Siempelkamp GmbH and Co., Kg., Germany) was used for hot pressing the composites. The platen temperature was set to $135^{\circ} \mathrm{C}$, whereas the initial pressure applied to the biocomposite panels were 7.1 $\mathrm{MPa}$ for a period of $2 \mathrm{~min}$, which was reduced to 4.7 MPa after another $2 \mathrm{~min}$ and $3.2 \mathrm{MPa}$ after following the similar time durations ( $2 \mathrm{~min}$ ). Later, the temperature is minimized to the environmental conditions through providing a cold water flow in the machine and the pressure was then totally released. The reason behind the extended time of pressing is performed for achieving the perfect curation of PF resin with the rice straw and energy reeds fiber. The extended duration of curing was also reported by another researcher where pMDI and UF bonded rice straw boards were produced (Li et al. 2010). However, the total time used for this current research to produce each biocomposite was 6 min which is much more lower than reported by another recent study (20 min) (Zhang and $\mathrm{Hu}$ 2014). On the other hand, reason behind the gradual decrease in pressure is to ensure a crack free and uniform composite panels. Otherwise, the panels could be destroyed if the pressure is released instantly. Finally, biocomposite panels were removed from the machine and kept in normal atmospheric conditions $\left(25{ }^{\circ} \mathrm{C}\right.$ temperature and $65 \%$ relative humidity). However, there were four biocomposite panels (Fig. 2) which were produced alike following the same operation protocols.

\section{Characterizations}

A moisture analyzer (Kern ULB 50-3 N, KERN AND SOHN GmbH, Germany) was used for investigating the moisture contents of fiber materials. However, accuracy of the equipment was $0.001 \mathrm{~g}$, whereas the temperature was $105 \pm 0.3{ }^{\circ} \mathrm{C}$. The standard EN 322:1993 was followed for moisture content investigations. Thermal conductivity of rice straw and energy reed fiber reinforced PF composites were investigated as per MSZ EN ISO 104562012 standard through following hot plate method at ambient atmospheric conditions (relative humidity $65 \pm 5 \%$ and temperature $20 \pm 2{ }^{\circ} \mathrm{C}$ ). The detailed procedures for the test is explained in our previous study (coir fiber reinforced MUF composites) (Hasan et al. 2021c). The mechanical performances of biocomposite panels were tested in terms of flexural properties (strength and modulus) and IBS through Instron testing machine (4208, United States). There were six samples from each composite type prepared and taken for the respective tests as per the standards. The standard EN 310 was followed for flexural properties investigation and EN 319 for IBS. Furthermore, morphological studies were conducted through a SEM equipment (S 3400 N, High Technologies Co., Ltd., Hitachi, Japan) by means of 100 and 200 times magnifications at $15.0 \mathrm{kV}$ for both unfractured and fractured samples.

\section{Results and discussion}

Density of the thermosetting polymer reinforced biocomposites play a significant role for determining thermomechanical properties of the products. Hence the densities of the biocomposites were also investigated. Although, the nominal densities were calculated to be $680 \mathrm{~kg} / \mathrm{m}^{3}$, but the actual densities found after the biocomposite formations were 713.66, 725, 742.79 , and $764.49 \mathrm{~kg} / \mathrm{m}^{3}$. Interestingly, it is observed that with the increase of energy reed fibers in the composite systems, density also started to increase whereas highest value was found for $100 \%$ energy reeds reinforced composite (with a $12.43 \%$ increase compared to the nominal density) whilst the lowest value was noticed for rice straw reinforced composite panels (with a $4.94 \%$ increase compared to nominal density). It maybe that the energy reed fibers are comparatively stronger than the rice straw, hence increased the density in composite systems. Furthermore, increased fiber porosity also influences the biocomposites density.

The load versus displacement curves of biocomposite panels are plotted in Fig. 3a, b both for flexural properties and IBS characteristics. The highest load was displayed by composite panel 4 (around 2096 N), whereas composite panel 1,2, and 3 showed approximately 673, 1019, and $1114 \mathrm{~N}$ loads, respectively. Conversely, in case of flexural properties, the values of load corresponding to the composite panel 1, 2, 3 and 4 are nearly 194, 225, 341, and $261 \mathrm{~N}$, respectively. However, after showing the maximum load for 
Fig. 2 Photographs of produced biocomposite panels produced from rice straw and energy reed fibers reinforced $\mathrm{PF}$ composites: a EH1, b EH2, c EH3, and d EH4
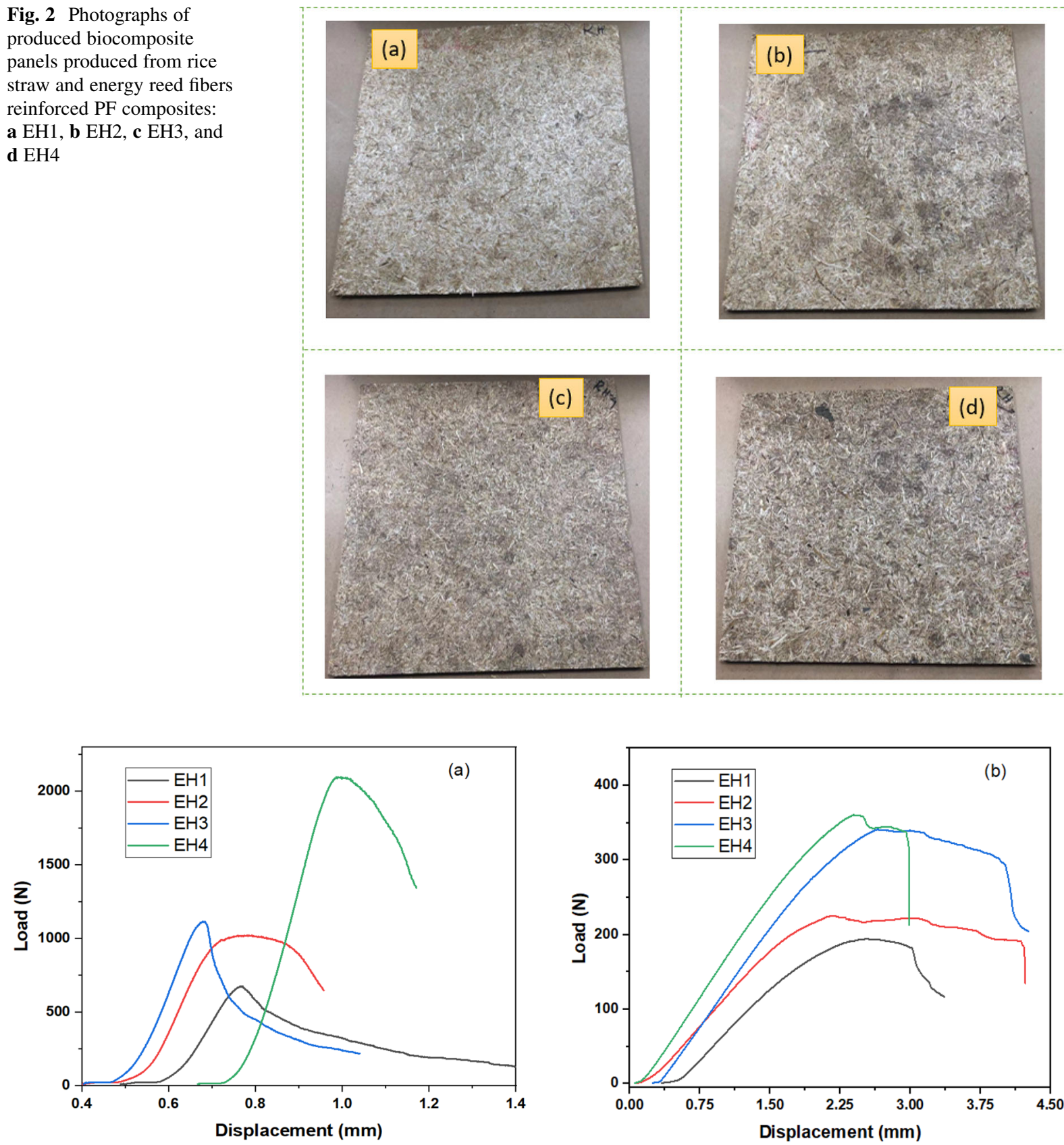

Fig. 3 Load versus displacement curves for energy reed and rice straw fibers reinforced PF composites: a IBS and $\mathbf{b}$ flexural properties

cracking of the test samples, still the load continues with the extended delaminations until the biocomposite panels total failure occurs. It is found that the $100 \%$ energy reed fibers reinforced biocomposites with PF resin requires the highest load for breaking/bending the samples compared to rice straw reinforced polymeric biocomposite panels. The similar effects were

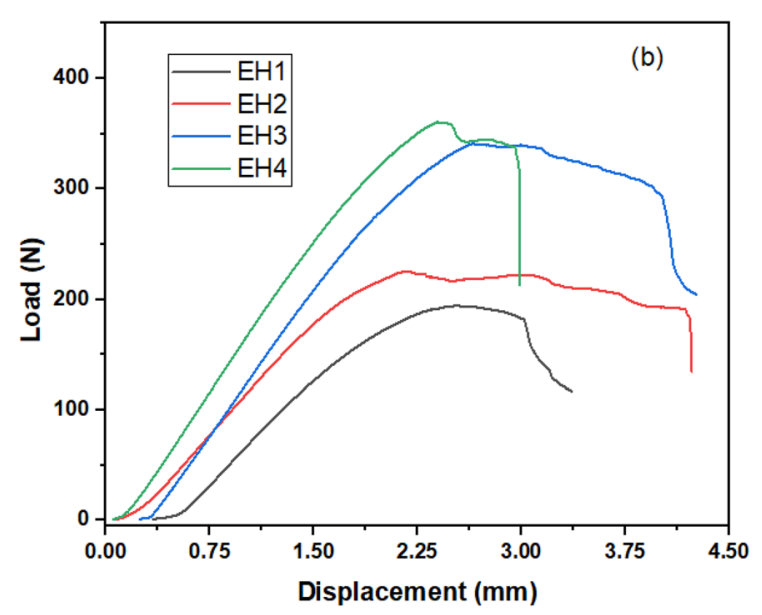

also reported in the previous studies for different natural fiber reinforced hybrid polymeric composites (De Olveira et al. 2018; Tran et al. 2015; Wong et al. 2010).

Mechanical characteristics of the developed composite panels from rice straw and energy reed fibers reinforced PF composites are tabulated in Table 3. The 
maximum value for MOR was seen for composite material 4 by 21.47 (2.12) MPa, whereas the lowest value was observed for composite material 1 just only 11.18 (1.91) $\mathrm{MPa}$ with a $47.9 \%$ decline from the composite 1. However, other two composite panels also showed the moderate results, whereas composite 2 provided 15.65 (3.91) MPa and composite 3 by 16.94 (2.02) $\mathrm{MPa}$. The differences in flexural strengths started to increase with the increase in energy reeds proportions in the composite systems. The similar trends are also noticed for the MOE and IBS properties. Likewise, composite 4 showed the highest MOE $8.73(0.16) \mathrm{MPa}$ and composite 1 by $5.42(0.69) \mathrm{MPa}$. Just except composite 2 (thickness value $9.52(0.18)$ $\mathrm{MPa}$ ), all other panels were showing the decreasing pattern of thicknesses (9.85 (0.31), 9.85 (0.11), and $9.58(0.04) \mathrm{MPa}$ ) (Table 3) with the increase in rice straws. It seems rice straws provided higher thickness compared to the energy reeds. The associated elongation at break (EBS) for flexural studies also showing dissimilar results, although the lowest value was found for composite 1 by $0.396(0.04) \%$, and highest values for composite 3 by $0.53(0.056) \%$. However, still composite 4 is showing higher values $(0.41(0.08) \%)$ compared to composite 1 panel.

IBS is another most important parameter to consider for the biocomposites performance analysis. The highest performances against internal bonding failure are displayed by the energy reed fiber reinforced composite panels $(0.52(0.04) \mathrm{MPa})$ compared to all other types of panel (0.25 (0.02), 0.31 (0.09), and 0.34 $(0.04) \mathrm{MPa}$ ) for composite 1, 2, and 3. The composite panel 4 showed a higher strength by $108 \%$ compared to composite $1,67.7 \%$ compared to composite 2 , and $52.9 \%$ compared to composite panel 3. Likewise, other mechanical properties (flexural strengths and modulus), IBS also provided the similar trends: the increase in performances depend on the increased loading of energy reed fibers proportion in hybrid composite system. However, still we could not find any report regarding the reinforcement of rice straw and energy reeds fiber reinforced hybrid composites to compare the performances, however the perceived results are providing satisfactory mechanical properties in case of medium density composite panels. Statistically, mechanical properties of the manufactured composite panels were tested further using coefficient of variation $\left(\mathrm{R}^{2}\right)$ in terms of energy reeds fiber proportions in composite systems. The $\mathrm{R}^{2}$ values for density, MOR, and MOE are higher than 0.5, whereas the values of IBS, T and E@BS are also higher than 0.41 . The $\mathrm{R}^{2}$ values of all the mechanical properties (Table 1) demonstrating a significant influence of energy reeds on the flexural properties of the developed materials. Hence, it could be stated that, the increased loading of energy reed fibers in composite system possesses a positive attributions for determining the different characteristics of biocomposite panels.

The morphological observations of rice straw and energy reed fibers provides a deep insight views of both material types (Fig. 1). However, the surfaces of fiber materials are seems to be rougher which is happened maybe for the alkaline pretreatment of the materials before the fabrication which also agrees with some other previous studies by the researchers (Zhang and $\mathrm{Hu}$ 2014). Furthermore, the rougher surfaces obtained through treatment of the materials could provide better mechanical properties to the composites too as the impurities like oil, wax, etc. are removed

Table 3 Mechanical characteristics of produced biocomposite panels from rice straw and energy reed fibers reinforced PF composites

\begin{tabular}{lllllll}
\hline BCs & $\begin{array}{l}\mathrm{D} \\
\left(\mathrm{kg} / \mathrm{m}^{3}\right)\end{array}$ & $\begin{array}{l}\text { MOR } \\
(\mathrm{MPa})\end{array}$ & $\begin{array}{l}\text { MOE } \\
(\mathrm{GPa})\end{array}$ & $\begin{array}{l}\mathrm{IBS} \\
(\mathrm{MPa})\end{array}$ & $\begin{array}{l}\mathrm{T} \\
(\mathrm{mm})\end{array}$ & $\begin{array}{l}\text { EBS } \\
(\%)\end{array}$ \\
\hline EH1 & $713.66(30.45)$ & $11.18(1.91)$ & $5.42(0.69)$ & $0.25(0.02)$ & $9.85(0.31)$ & $0.396(0.04)$ \\
EH2 & $725(21.01)$ & $15.65(3.91)$ & $6.64(0.66)$ & $0.31(0.09)$ & $9.52(0.18)$ & $0.523(0.066)$ \\
EH3 & $742.79(16.51)$ & $16.94(2.02)$ & $7.85(0.25)$ & $0.34(0.04)$ & $9.85(0.11)$ & $0.53(0.056)$ \\
EH4 & $764.49(8.28)$ & $21.47(2.12)$ & $8.73(0.16)$ & $0.52(0.04)$ & $9.58(0.04)$ & $0.41(0.08)$ \\
Coefficient of variation $\left(\mathrm{R}^{2}\right)$ & 0.50 & 0.64 & 0.85 & 0.41 & 0.49 & 0.46 \\
\hline
\end{tabular}

* $D$ Density; MOR Modulus of Rupture; MOE Modulus of Elasticity; IBS Internal Bonding Strength; T Thickness; EBS Elongation at bending stress 
from the cellulosic materials. The morphological photographs of unfractured surfaces (Fig. 4) are displaying flat and uniform coating of PF resins over the fiber surfaces demonstrating a stronger bonding in composite systems. The reason behind the strong reinforcement effects between the fiber and polymers is mediated by the pretreatment of the rice straw (Kalagar et al. 2011) and energy reeds materials. Although the fibers are somehow appeared in the unfractured surfaces, but the clear representative fibers could be seen explicitly in fractured surfaces (Fig. 5). Overall, it could be summarized that a better reinforcement effect is achieved through pretreating rice straw and energy reeds before the defibration and fabrications which also in agreement with the previous reports by the researchers (Wang et al. 2018).

Furthermore, the presence of chemical elements in the biocomposite panels were also studied in terms of SEM mediated EDX (energy-dispursive X-ray) spectra to investigate the constituents of the materials. The main chemical elements of natural fibers are carbon (C) and oxygen (O) (Hasan et al. 2021f; Manimaran et al. 2018) which are detected as the broad peaks in Fig. 6a, b. however, the presence of $\mathrm{C}$ and $\mathrm{O}$ could also be observed for all the composites as well (Fig. 6c-f). Moreover, there is also a signal detected for the presence of chlorine $(\mathrm{Cl})$, Aluminum $(\mathrm{Al})$, potassium $(\mathrm{K})$ in the composite panels which is maybe responsible for using the tape waters or processing equipments during preparing the materials in different stages appeared as impurities. However, the prominence of $\mathrm{C}$ and $\mathrm{H}$ is found to have increased especially for Fig. 6e, h compared to Fig. 6a, b. The PF resin also contains $\mathrm{H}$ (hydrogen) and carbon in their polymeric structures which may have consequence for this changes in the composite systems. Hence, the overall discussions confirm a strong and successful binding of $\mathrm{PF}$ resin with the cellulosic energy reeds and rice straw fibers.

Thermal conductivity is a critical performance and reliability assessment parameters of polymeric composite panels for structural and construction materials. The types of finer and associated volume fraction of fiber materials play a significant role for improved thermal conductivity of natural fiber reinforced composites (Mounika et al. 2012). It is found that composite panel 1 displayed lowest values of thermal conductivity $(0.061(0.00083)) \mathrm{W} /(\mathrm{m} . \mathrm{K})$, whereas the highest values found for $100 \%$ energy reed fibers reinforced composites $(0.104790(0.000571))$. Moreover, the values of EH@2 and EH@3 composites are providing $0.10383(0.00061)$ and 0.10447 (0.00069) $\mathrm{W} /(\mathrm{m} . \mathrm{K})$ thermal conductivity. It is noticed that thermal conductivity also showing an increasing trends like as mechanical properties with the increased loading of energy reeds in composites system. In our previous study (Hasan et al. 2021b) for coir fiber and fibrous chips reinforced with MUF polymeric composite panels (medium density), we have found the thermal conductivity values between $0.09302 \pm 00.999$ and $0.1078 \pm 00.0072 \mathrm{~W} /(\mathrm{m} . \mathrm{K})$. In another study by Ramanaiah et al. (2011) for Typha angustifolia reinforced polyester composites (high density) showed the thermal conductivity between 0.137 and $0.432 \mathrm{~W} /(\mathrm{mK})$. However, the obtained thermal conductivity reported in this current study is found to provide comparatively better results demonstrating the produced biocomposite panels could perform as prominent insulation materials. However, the density could be enhanced from medium to higher for attaining lower values of thermal conductivity which could be utilized as a potential building material. Additionally, rice straw reinforced composites provided better thermal conductivity values although the mechanical properties found were not competitive compared to energy reed fibers reinforced panels.

The functional groups of cellulosic materials used in this research were detected further in terms of FTIR spectra (Fig. 7). Both the rice straw and energy reeds are displaying broad absorption peaks within $3600-3200 \mathrm{~cm}^{-1}$ wavelength demonstrating the presence of $-\mathrm{OH}$ groups in their polymeric structures (Ismail et al. 2011; Qin 2011). However, the similar peaks also still could be noticed after the fabrication of biocomposites. The peaks become broader after the reinforcement maybe due to the reinforcement with $\mathrm{PF}$ resin. The peaks at around 2921 and $2852 \mathrm{~cm}^{-1}$ is indicating the $\mathrm{C}=\mathrm{H}$ stretching vibrations (Arshad 2021; Qin et al. 2011). Moreover, peaks at $1733 \mathrm{~cm}^{-1}$ is related to the lignin fractions present in the naturally derived materials. The absorption band at $1507 \mathrm{~cm}^{-1}$ is assigned for the vibrations of aromatic ring. The presence of primary alcohol is confirmed by the peaks at $1032 \mathrm{~cm}^{-1}$ (El Mansouri et al. 2018). The overall detection of different chemical bonding in the composite materials demonstrate a successful 

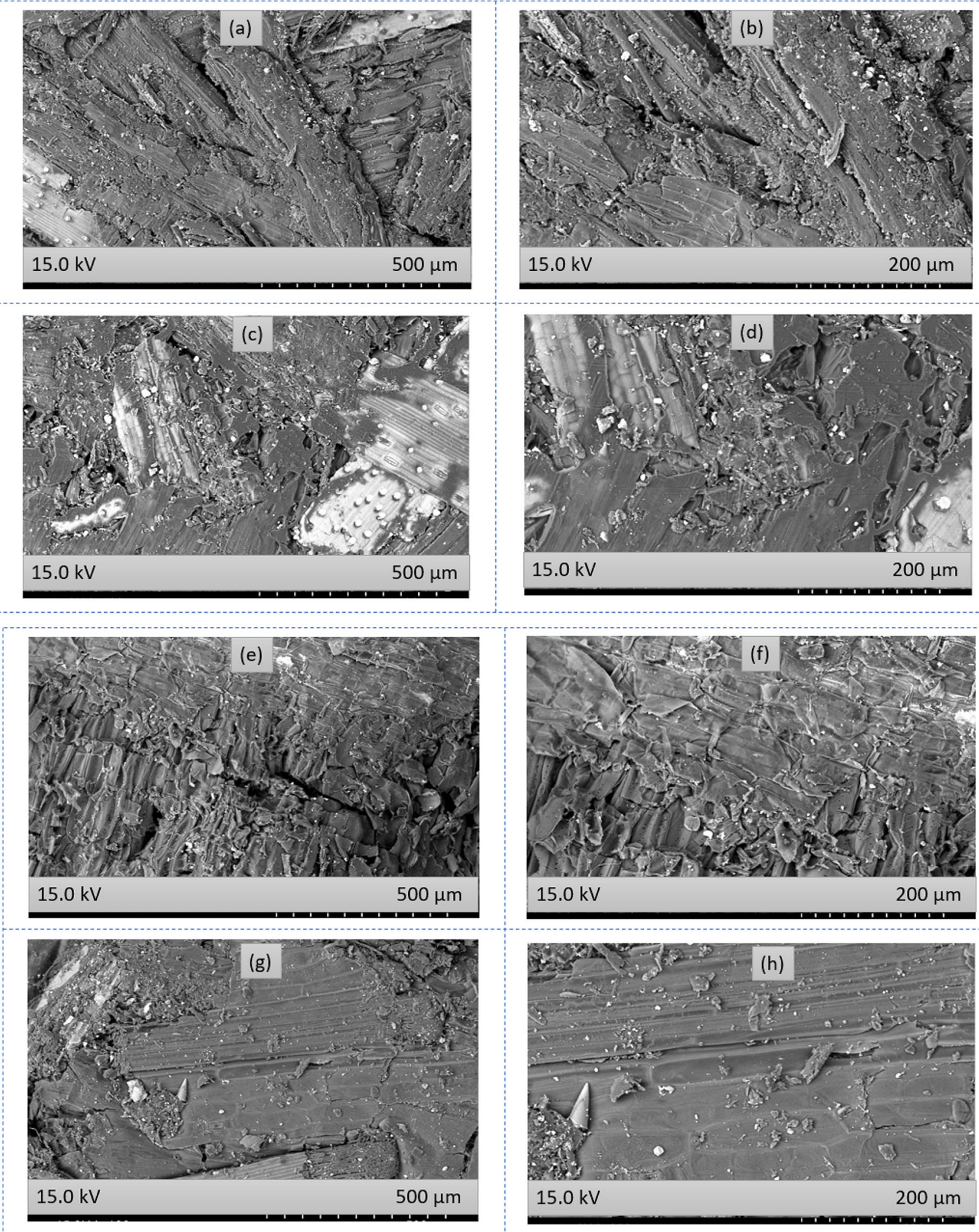

Fig. 4 SEM micrographs of biocomposite panels (before fracture) from rice straw and energy reed fibers reinforced PF composites at different magnifications a and b EH1; $\mathbf{c}$ and $\mathbf{d} \mathrm{EH} 2 ; \mathbf{e}$ and $\mathbf{f} \mathrm{EH} 3 ; \mathbf{g}$ and $\mathbf{h} \mathrm{EH} 4$ 

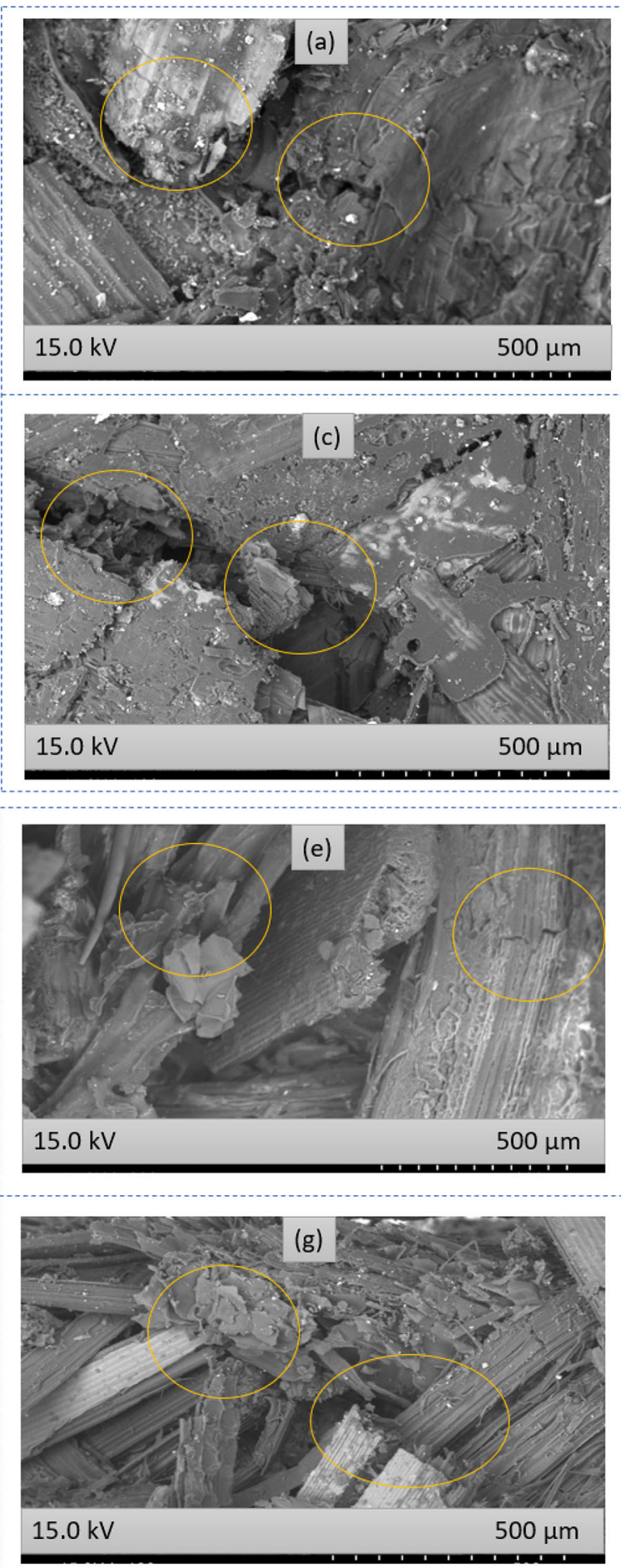
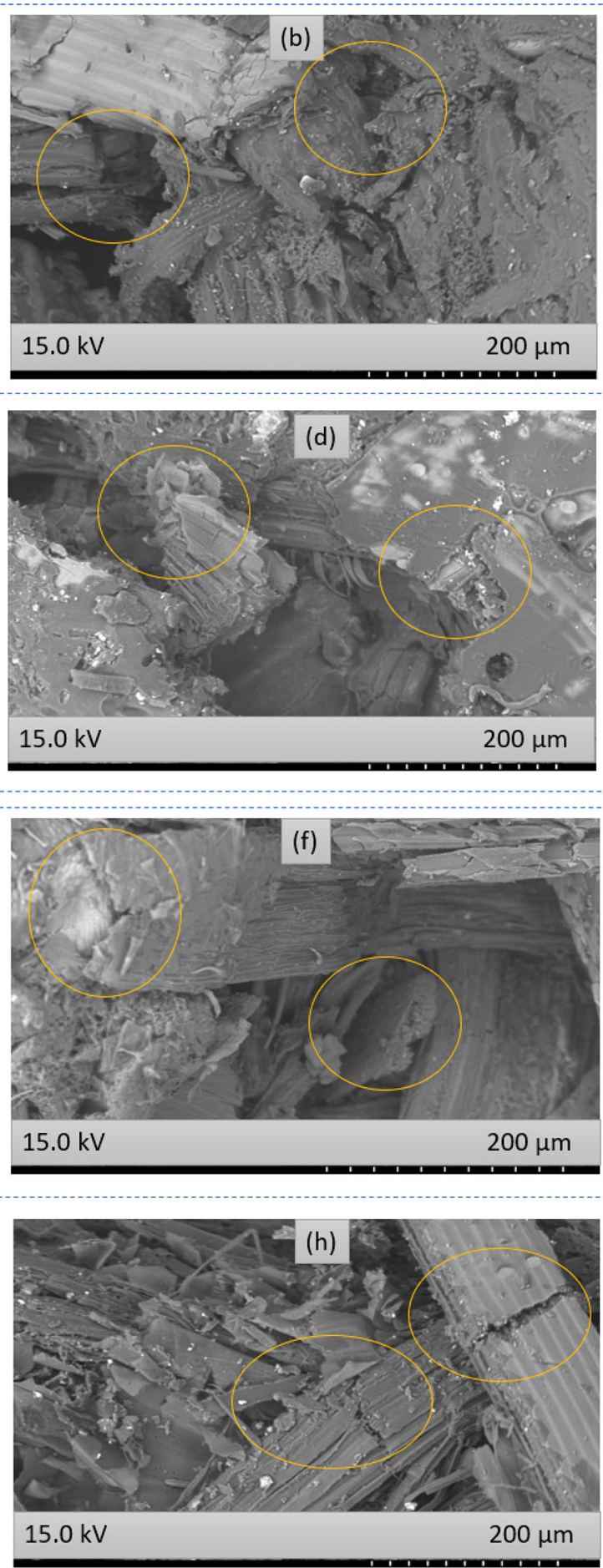

Fig. 5 SEM micrographs of fractured biocomposite panels from rice straw and energy reed fibers reinforced with PF resin at different magnifications: $\mathbf{a}$ and $\mathbf{b} \mathrm{EH} 1 ; \mathbf{c}$ and $\mathbf{d} \mathrm{EH} 2 ; \mathbf{e}$ and $\mathbf{f} \mathrm{EH} 3 ; \mathbf{g}$ and $\mathbf{h} \mathrm{EH} 4$ 

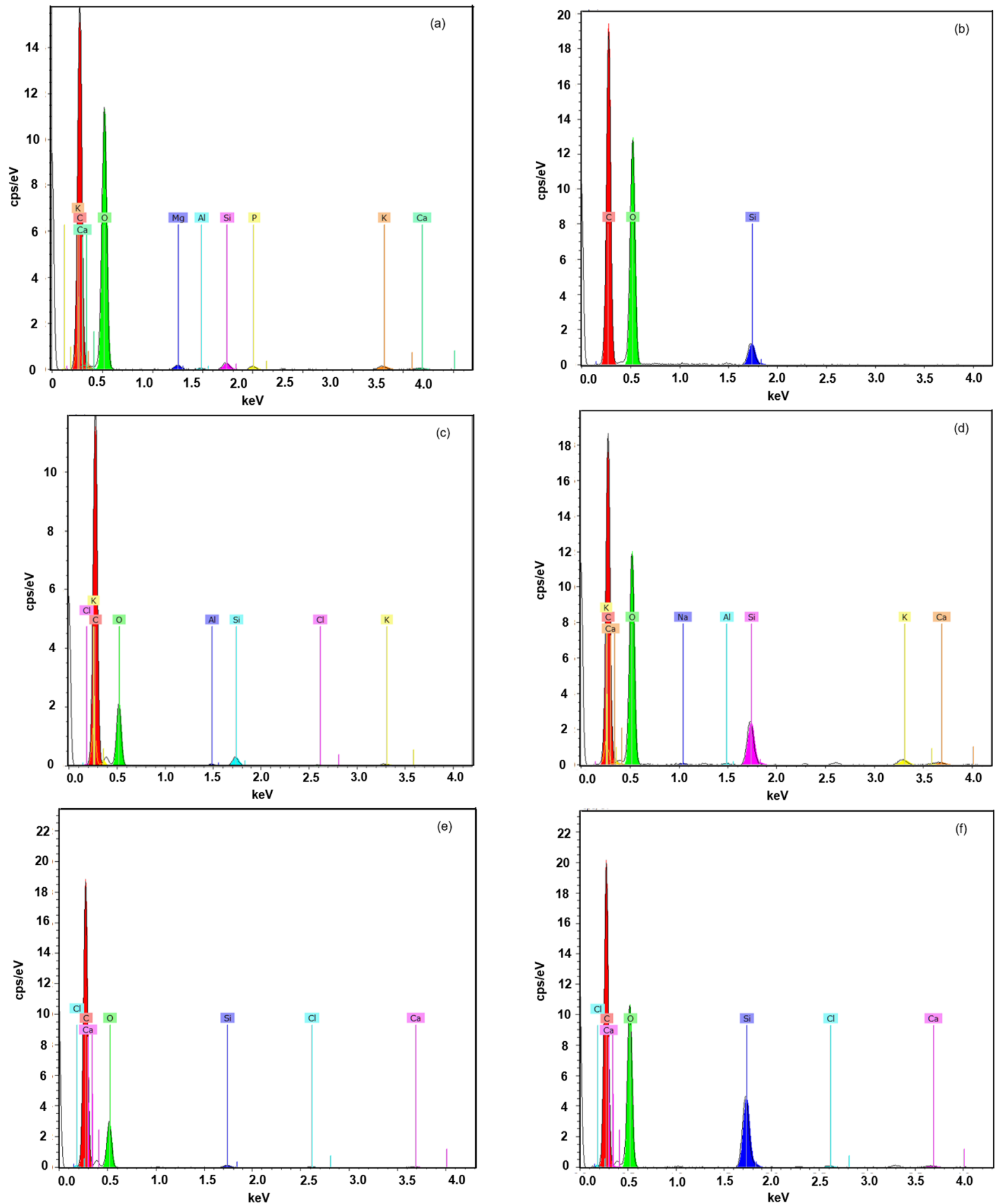

Fig. 6 EDX spectra of produced biocomposite panels from rice straw and energy reed fibers reinforced with PF resin: a energy reeds fiber; b rice straw fiber; c EH1; d EH2; e EH3; f EH4 


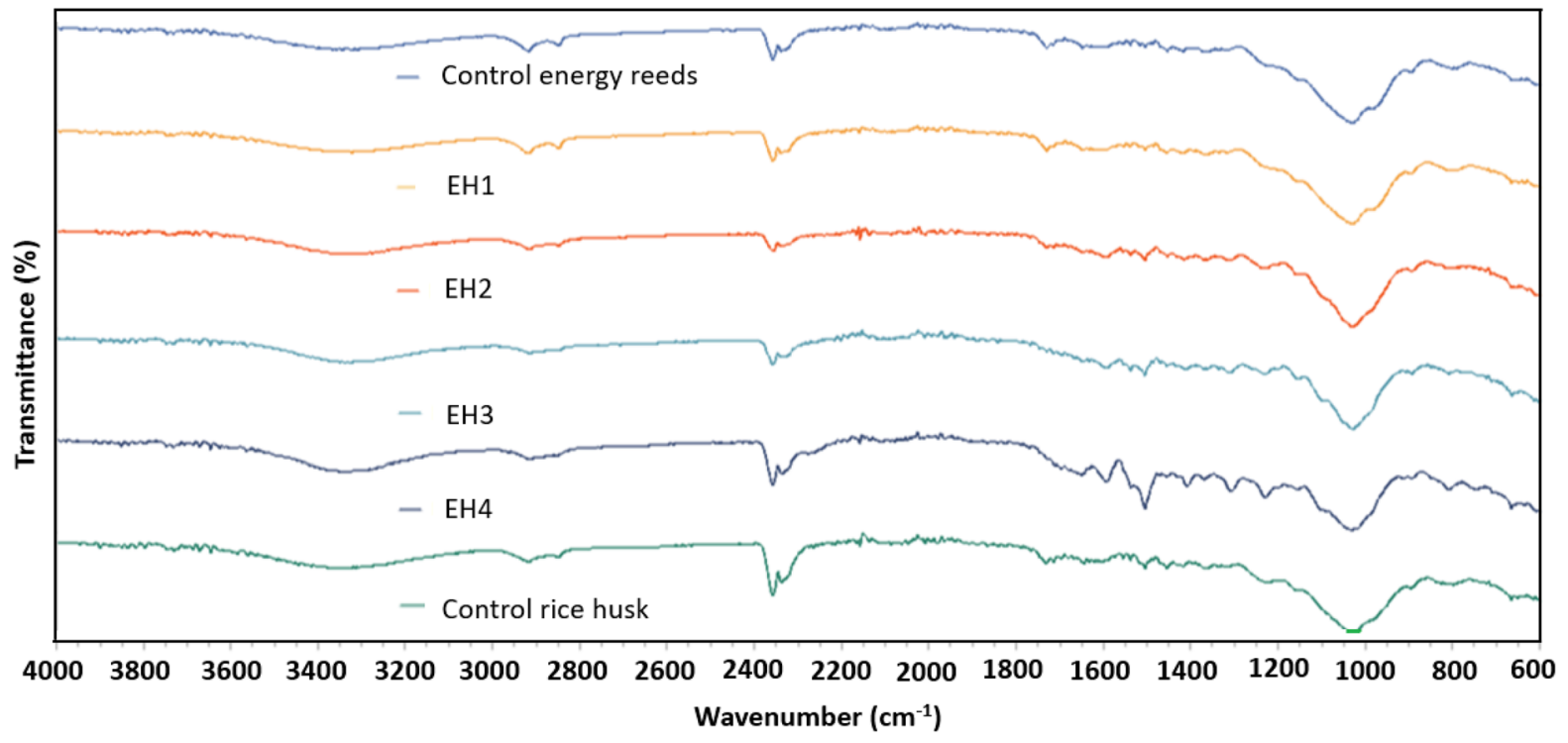

Fig. 7 FTIR spectra of control energy reed, rice straw, and associated biocomposites

reinforcement effects between the natural fibers and PF resin.

The water absorbency, thickness swelling, and physical properties are the key parameters for investigating physical properties of biocomposite materials (Fig. 8). All the properties were measured for 2 and $24 \mathrm{~h}$ duration of times. The water absorbency and thickness swelling properties were tested after immersion of the hybrid biocomposite samples under the water. Compared to the artificial fibers, natural fiber reinforced composites absorb higher water and moisture from the surrounding atmosphere (Hasan et al. 2021f). The cause of higher water absorption is due to the presence of some hydrophilic chemical compounds like $-\mathrm{CO},-\mathrm{COOH},-\mathrm{NH}_{2}$, and $-\mathrm{OH}$, in the natural fibers polymeric structures (Hasan et al. 2021e, 2021f). The water absorption, thickness swelling, and moisture content studies of the developed hybrid biocomposite panels shown that $100 \%$ rice straw reinforced composites provided the maximum values (54.284 (2.6580)\% for water absorbency, $38.572(0.1744) \%$ for thickness swelling, and 5.92 (0.6464)\% for moisture content) whereas the energy reed fiber $(100 \%)$ reinforced composites provided the lowest values $(7.746(0.3391) \%$ for water absorbency, $9.383(0.5115) \%$ for thickness swelling, and 5.11 $(0.2423) \%$ for moisture content) after $2 \mathrm{~h}$. However, the similar trend is also noticed after $24 \mathrm{~h}$ although the absorption rates started to decline gradually after $2 \mathrm{~h}$.
The sequence of the physical properties in terms of higher values is EH1 $>\mathrm{EH} 2>\mathrm{EH} 3>\mathrm{EH} 4$ for the composite panels. It is seen that energy reed fiber loaded biocomposites absorb less moisture and water compared to the rice straw loaded biocomposites. However, the moisture content in the hybrid composite systems start to decrease with the increased loading of energy reeds in the proportions. The similar phenomenon were also discussed by the researchers in previous studies for different natural fiber reinforced polymeric composites (Bera et al. 2019; Hasan et al. 2021d; Njoku et al. 2019; Vinod 2021).

\section{Conclusions}

The reinforcement of rice straw and energy reed fibers for hybrid biocomposites production through using hot-pressing technology is a feasible and convenient manufacturing approach. The mechanical properties (IBS and flexural properties), thermal conductivity, and physical properties in terms of moisture content, water absorbency, and thickness swelling stability are found satisfactory with an increasing trend whilst the energy reeds incorporation was increased in the composite system. The EDX analysis provided the peaks for different chemical elements which are demonstrating a strong binding between the cellulosic rice straw and energy reed fibers with PF resin. The 

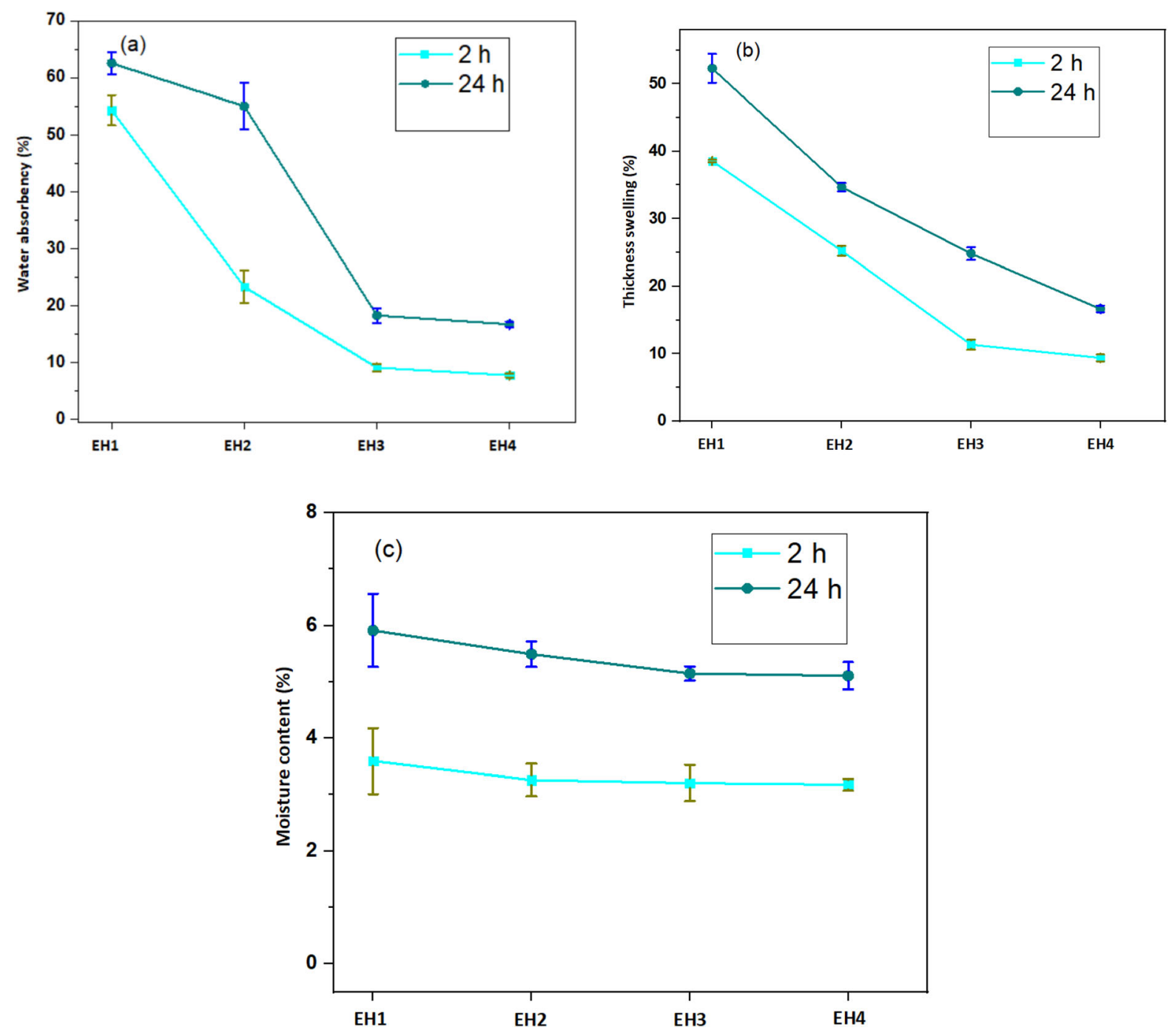

Fig. 8 Physical properties of developed biocomposites: a water absorbency, $\mathbf{b}$ thickness swelling, and $\mathbf{c}$ moisture content

morphological characteristics also further shown a strong coating of PF resin with rice straw and energy reed reinforcement materials. The thermal conductivity tests provided significant potentiality of the biocomposite panels as prominent insulation materials. In this regard, the developed composites exhibited a superior potentiality for particle boards production, structural applications, light weight vehicles, and so on. Furthermore, energy reed fibers are also found to have a prominent potential as the reinforcement materials in the near futures. Moreover, this research work shown a new potentiality for future researchers and industrial production houses with novel hybrid biocomposite materials from renewable sources.
Acknowledgments This work was supported by the "Stipendium Hungaricum" scholarship under the Simonyi Károly Faculty of Engineering, Wood Sciences, and Applied Arts, University of Sopron, Hungary. This article was produced within the framework of "EFOP-3.6.1-16-2016-00018: improving the role of research, development and innovation in the higher education through institutional developments assisting intelligent specialization in Sopron and Szombathely". Authors are also grateful to Kun Gábor, Zsófia Kóczán, Pásztory Zoltán, and Kovács Zsolt (University of Sopron) for their cooperations during this research.

Author contributions KMFH and ZMM generated the idea, conducted the experiment, data curation, and written the initial draft. MB and LDHA cooperated for testing. PGH and TA helped for project administration, data validation, and final draft review. 
Funding Open access funding provided by University of Sopron.

\section{Declarations}

Conflict of interest The authors declare that they have no conflicts of interest for the submitted work.

Ethical approval This research does not contain any investigation related to human participation or any animals conducted by the authors. In this regard, authors are claiming the compliance of this work with ethical standards.

Open Access This article is licensed under a Creative Commons Attribution 4.0 International License, which permits use, sharing, adaptation, distribution and reproduction in any medium or format, as long as you give appropriate credit to the original author(s) and the source, provide a link to the Creative Commons licence, and indicate if changes were made. The images or other third party material in this article are included in the article's Creative Commons licence, unless indicated otherwise in a credit line to the material. If material is not included in the article's Creative Commons licence and your intended use is not permitted by statutory regulation or exceeds the permitted use, you will need to obtain permission directly from the copyright holder. To view a copy of this licence, visit http://creativecommons.org/licenses/by/4.0/.

\section{References}

Antunes A, Faria P, Silva V, Brás AJC, Materials B (2019) Rice husk-earth based composites: a novel bio-based panel for buildings refurbishment. Con Build Mater 221:99-108. https://doi.org/10.1016/j.conbuildmat.2019.06.074

Arshad MN et al (2021) Effect of coir fiber and TiC nanoparticles on basalt fiber reinforced epoxy hybrid composites: physico-mechanical characteristics. Cellulose 28:3451-3471. https://doi.org/10.1007/s10570-02103752-7

Basta AH, El-Saied H, Lotfy VF (2013) Performance of rice straw-based composites using environmentally friendly polyalcoholic polymers-based adhesive system. Pigment Resin Technol. https://doi.org/10.1108/ 03699421311288733

Bera T, Mohanta N, Prakash V, Pradhan S, Acharya SK (2019) Moisture absorption and thickness swelling behaviour of luffa fibre/epoxy composite. J Reinf Plast Compos 38:923-937

De Olveira LÁ, Santos JCd, Panzera TH, Freire RTS, Vieira LMG, Rubio JCC (2018) Investigations on short coir fibrereinforced composites via full factorial design. Polym Polym Compos 26:391-399. https://doi.org/10.1177/ 0967391118806144

El Mansouri NE, Yuan Q, Huang F (2018) Preparation and characterization of phenol-formaldehyde resins modified with alkaline rice straw lignin. BioResources
13:8061-8075. https://doi.org/10.15376/biores.13.4.80618075

El-Kassas A, Mourad AI (2013) Novel fibers preparation technique for manufacturing of rice straw based fiberboards and their characterization. Mater Des 50:757-765. https:// doi.org/10.1016/j.matdes.2013.03.057

El-Sabbagh A (2014) Effect of coupling agent on natural fibre in natural fibre/polypropylene composites on mechanical and thermal behaviour. Compos Part B Eng 57:126-135. https://doi.org/10.1016/j.compositesb.2013.09.047

Energianövény (2021) Resources for the future. http://www. energianoveny.hu/. Accessed 14th March 2021

Faruk O, Bledzki AK, Fink H-P, Sain M (2012) Biocomposites reinforced with natural fibers: 2000-2010. Prog Polym Sci 37:1552-1596. https://doi.org/10.1016/j.progpolymsci. 2012.04.003

Ferdosian F, Pan Z, Gao G, Zhao B (2017) Bio-based adhesives and evaluation for wood composites application. Polymers 9:70. https://doi.org/10.3390/polym 9020070

Fuqua MA, Huo S, Ulven CA (2012) Natural fiber reinforced composites. Polym Rev 52:259-320. https://doi.org/10. 1080/15583724.2012.705409

Gallos A, Paës G, Allais F, Beaugrand J (2017) Lignocellulosic fibers: a critical review of the extrusion process for enhancement of the properties of natural fiber composites. RSC Adv 7:34638-34654. https://doi.org/10.1039/ C7RA05240E

Getme AS, Patel B (2020) A review: bio-fiber's as reinforcement in composites of polylactic acid (PLA). Mater Today 26:2116-2122. https://doi.org/10.1016/j.matpr.2020.02. 457

Gholampour A, Ozbakkaloglu T (2020) A review of natural fiber composites: properties, modification and processing techniques, characterization, applications. J Mater Sci 55:829-892. https://doi.org/10.1007/s10853-019-03990-y

Hasan K, Horváth PG, Alpár T (2020a) Potential natural fiber polymeric nanobiocomposites: a review. Polymers 12:1072. https://doi.org/10.3390/polym12051072

Hasan KMF, Horváth PG, Alpár T (2020b) Potential natural fiber polymeric nanobiocomposites: a review. Polymers 12:1-25. https://doi.org/10.3390/polym12051072

Hasan KF, Horváth PG, Bak M, Alpár T (2021a) A state-of-theart review on coir fiber-reinforced biocomposites. RSC Adv 11:10548-10571. https://doi.org/10.1039/ D1RA00231G

Hasan KF, Horváth PG, Kóczán Z, Alpár T (2021b) Thermomechanical properties of pretreated coir fiber and fibrous chips reinforced multilayered composites. Sci Rep 11:1-13. https://doi.org/10.1038/s41598-021-83140-0

Hasan KF, Horváth PG, Kóczán Z, Alpár T (2021c) Thermomechanical properties of pretreated coir fiber and fibrous chips reinforced multilayered composites. Sci Rep. https:// doi.org/10.1038/s41598-021-83140-0

Hasan KF, Horváth PG, Markó G, Alpár T (2021d) Thermomechanical characteristics of flax-woven-fabric-reinforced poly (lactic acid) and polypropylene biocomposites. Green Mater 40:1-10. https://doi.org/10.1680/jgrma.20.00052

Hasan KF, Horváth PG, Miklos B, Alpár T (2021e) A state-ofthe-art review on coir fiber-reinforced biocomposites. RSC Adv 11:10548-10571. https://doi.org/10.1039/d1ra00231g 
Hasan KF, PtGr H, Alpár T (2021f) Thermomechanical behavior of methylene diphenyl diisocyanate-bonded flax/glass woven fabric reinforced laminated composites. ACS Omega 6:6124-6133. https://doi.org/10.1680/jgrma. 20.00052

Hasan KMF, Horváth PG, Alpár T (2021g) Development of lignocellulosic fiber reinforced cement composite panels using semi-dry technology. Cellulose 28:3631-3645. https://doi.org/10.1007/s10570-021-03755-4

Hasan KMF, Horváth PG, Alpár T (2021h) Lignocellulosic fiber cement compatibility: a state of the art review. J Nat Fibers. https://doi.org/10.1080/15440478.2021.1875380

Holbery J, Houston D (2006) Natural-fiber-reinforced polymer composites in automotive applications. Jom 58:80-86. https://doi.org/10.1007/s11837-006-0234-2

Ismail M, Yassen AA, Afify M (2011) Mechanical properties of rice straw fiber-reinforced polymer composites. Fibers Polym 12:648-656. https://doi.org/10.1007/s12221-0110648-5

Jagadeesh P, Thyavihalli Girijappa YG, Puttegowda M, Rangappa SM, Siengchin S (2020) Effect of natural filler materials on fiber reinforced hybrid polymer composites: an overview. J Nat Fiber. https://doi.org/10.1080/ 15440478.2020.1854145

Kalagar M, Khademieslam H, Bazyar B, Hejazi S (2011) Morphology and mechanical properties of alkali-treated rice straw flour-polypropylene composites. BioResources 6:4238-4246. https://doi.org/10.15376/biores.6.4.42384246

Kalia S, Kaith B, Kaur I (2009) Pretreatments of natural fibers and their application as reinforcing material in polymer composites-A review. Polym Eng Sci 49:1253-1272. https://doi.org/10.1002/pen.21328

Li X, Cai Z, Winandy JE, Basta AH (2010) Selected properties of particleboard panels manufactured from rice straws of different geometries. Biores Technol 101:4662-4666. https://doi.org/10.1016/j.biortech.2010.01.053

Li Z, Wu F, Zhao L, Lin X, Shen L, Feng Y (2018) Evaluation of fundamental and functional properties of natural plant product powders for direct compaction based on multivariate statistical analysis. Adv Powder Technol 29:2881-2894. https://doi.org/10.1016/j.apt.2018.08.009

Ma Y, Liu Y, Shang W, Gao Z, Wang H, Guo L, Tong J (2014) Tribological and mechanical properties of pine needle fiber reinforced friction composites under dry sliding conditions. RSC Adv 4:36777-36783. https://doi.org/10.1039/ C4RA06717G

Mahmud S, Hasan KF, Jahid MA, Mohiuddin K, Zhang R, Zhu J (2021) Comprehensive review on plant fiber-reinforced polymeric biocomposites. J Mater Sci 56:7231-7264. https://doi.org/10.1007/s10853-021-05774-9

Manimaran P, Senthamaraikannan P, Sanjay M, Marichelvam M, Jawaid M (2018) Study on characterization of Furcraea foetida new natural fiber as composite reinforcement for lightweight applications. Carbohydr Polym 181:650-658. https://doi.org/10.1016/j.carbpol.2017.11.099

Matsuzaki R et al (2016) Three-dimensional printing of continuous-fiber composites by in-nozzle impregnation. Sci Rep 6:1-7. https://doi.org/10.1038/srep23058

Mishra S et al (2003) Studies on mechanical performance of biofibre/glass reinforced polyester hybrid composites.
Compos Sci Technol 63:1377-1385. https://doi.org/10. 1016/S0266-3538(03)00084-8

Mokhothu TH, John MJ (2017) Bio-based coatings for reducing water sorption in natural fibre reinforced composites. Sci Rep 7:1-8. https://doi.org/10.1038/s41598-017-13859-2

Mounika M, Ramaniah K, Prasad AR, Rao KM, Reddy KHC (2012) Thermal conductivity characterization of bamboo fiber reinforced polyester composite. J Mater Environ Sci 3:1109-1116

Njoku C, Omotoyinbo J, Alaneme K, Daramola M (2019) Chemical modification of Urena lobata (Caeser weed) fibers for reinforcement applications. J Phys Conf Ser 1378:1-6. https://doi.org/10.1088/1742-6596/1378/2/ 022015

Nouri M, Tahlaiti M, Grondin F, Belarbi R (2020) The influence of chemical and thermal treatments on the diss fiber hygroscopic behaviors. J Nat Fibers. https://doi.org/10. 1080/15440478.2020.1848733

Pham TD, Vu CM, Choi HJJPS, Series A (2017) Enhanced fracture toughness and mechanical properties of epoxy resin with rice husk-based nano-silica. Polym Sci 59:437-444. S0965545X17030026

https://doi.org/10.1134/

Qin L et al (2011) Mechanical and thermal properties of poly (lactic acid) composites with rice straw fiber modified by poly (butyl acrylate). Chem Eng J 166:772-778. https:// doi.org/10.1016/j.cej.2010.11.039

Ramamoorthy SK, Skrifvars M, Persson A (2015) A review of natural fibers used in biocomposites: plant, animal and regenerated cellulose fibers. Polym Rev 55:107-162

Ramanaiah K, Ratna Prasad A, Chandra Reddy KH (2011) Mechanical properties and thermal conductivity of Typha angustifolia natural fiber-reinforced polyester composites. Int J Polym Anal Charact 16:496-503. https://doi.org/10. 1080/1023666X.2011.598528

Rangappa SM, Siengchin S, Dhakal HN (2020) Green-composites: ecofriendly and sustainability. Appl Sci Eng Prog 13:183-184. https://doi.org/10.14416/j.asep.2020.06.001

Rokbi M, Osmani H, Imad A, Benseddiq NJpE, (2011) Effect of chemical treatment on flexure properties of natural fiberreinforced polyester composite. Eng Procedia 10:2092-2097. https://doi.org/10.1016/j.proeng.2011.04. 346

Rout A, Satapathy AJPE (2012) Analysis of dry sliding wear behaviour of rice husk filled epoxy composites using design of experiment and ANN. Procedia Eng 38:1218-1232. https://doi.org/10.1016/j.proeng.2012.06. 153

Sanjay M, Siengchin S (2021) Editorial corner-a personal view exploring the applicability of natural fibers for the development of biocomposites. Xpress Polym Lett 15:193. https://doi.org/10.3144/expresspolymlett.2021.17

Sanjay M, Siengchin S, Parameswaranpillai J, Jawaid M, Pruncu CI, Khan A (2019) A comprehensive review of techniques for natural fibers as reinforcement in composites: preparation, processing and characterization. Carbohydr Polym 207:108-121. https://doi.org/10.1016/j.carbpol.2018.11. 083

Shubhra QT et al (2010) Characterization of plant and animal based natural fibers reinforced polypropylene composites 
and their comparative study. Fiber Polym 11:725-731. https://doi.org/10.1007/s12221-010-0725-1

Thyavihalli Girijappa YG, Mavinkere Rangappa S, Parameswaranpillai J, Siengchin S (2019) Natural fibers as sustainable and renewable resource for development of eco-friendly composites: a comprehensive review. Front Mater 6:1-14. https://doi.org/10.3389/fmats.2019.00226

Tran LQN, Minh TN, Fuentes C, Chi TT, Van Vuure AW, Verpoest I (2015) Investigation of microstructure and tensile properties of porous natural coir fibre for use in composite materials. Ind Crops Prod 65:437-445. https:// doi.org/10.1016/j.indcrop.2014.10.064

Vinod A et al (2021) Novel Muntingia Calabura bark fiber reinforced green-epoxy composite: a sustainable and green material for cleaner production. J Clean Prod 294:126337. https://doi.org/10.1016/j.jclepro.2021.126337

Wahid R, Nielsen SF, Hernandez VM, Ward AJ, Gislum R, Jørgensen U, Møller HB (2015) Methane production potential from Miscanthus sp.: effect of harvesting time, genotypes and plant fractions. Biosyst Eng 133:71-80. https://doi.org/10.1016/j.biosystemseng.2015.03.005

Wang C-z, Li F-y, Wang L-m, Li J-f, Guo A-f, Zhang C-w, Liu P (2015) Research on thermoplastic starch and different fiber reinforced biomass composites. RSC Adv 5:49824-49830. https://doi.org/10.1039/C5RA08278A

Wang Z, Qiao X, Sun K (2018) Rice straw cellulose nanofibrils reinforced poly (vinyl alcohol) composite films. Carbohydr Polym 197:442-450. https://doi.org/10.1016/j.carbpol. 2018.06.025
Wong K, Zahi S, Low K, Lim C (2010) Fracture characterisation of short bamboo fibre reinforced polyester composites. Mater Des 31:4147-4154. https://doi.org/10.1016/j. matdes.2010.04.029

Xia C et al (2016) Hybrid boron nitride-natural fiber composites for enhanced thermal conductivity. Sci Rep 6:1-8. https:// doi.org/10.1038/srep34726

Xie X, Zhou Z, Jiang M, Xu X, Wang Z, Hui D (2015) Cellulosic fibers from rice straw and bamboo used as reinforcement of cement-based composites for remarkably improving mechanical properties. Compos Part B Eng 78:153-161. https://doi.org/10.1016/j.compositesb.2015.03.086

Yin P, Chen C, Ma H, Gan H, Guo B, Li P (2020) Surface crosslinked thermoplastic starch with different UV wavelengths: mechanical, wettability, hygroscopic and degradation properties. RSC Adv 10:44815-44823. https://doi.org/10. 1039/D0RA07549C

Zhang L, Hu Y (2014) Novel lignocellulosic hybrid particleboard composites made from rice straws and coir fibers. Mater Des 55:19-26. https://doi.org/10.1016/j.matdes. 2013.09.066

Zhang K, Wang F, Liang W, Wang Z, Duan Z, Yang B (2018) Thermal and mechanical properties of bamboo fiber reinforced epoxy composites. Polymers 10:608. https://doi.org/ 10.3390/polym 10060608

Publisher's Note Springer Nature remains neutral with regard to jurisdictional claims in published maps and institutional affiliations. 